\title{
Research on Teaching Quality Assurance in Chinese-foreign Cooperative Programs
}

\author{
Haiying Ma ${ }^{1, a^{*}}$ and Yajian Sun ${ }^{2, b}$ \\ ${ }^{1,2}$ School of Economics, Northwest Minzu University, Lanzhou (730124), P.R.China \\ alxmahaiying8888@163.com, b 760336805@qq.com
}

\begin{abstract}
Keywords: Higher education; Chinese-foreign cooperative programs; Quality of Education; Quality Control
\end{abstract}

\begin{abstract}
Chinese-foreign cooperative program is an inevitable choice for China's higher education to conform to the trend of internationalization of education, and also an important way to explore and improve the quality of higher education in China. Through the cooperative of Chinese and foreign cooperative, the international vision of students can be effectively opened up and their international competitiveness can be enhanced. In order to achieve long-term development, we must adhere to the principle of quality first and strengthen the monitoring of the quality of education. Under the guidance of certain principles, we must establish a scientific, comprehensive and strict monitoring system and mechanism so as to promote the continuous development of higher education.
\end{abstract}

\section{Introduction}

Chinese and foreign cooperative in running a school is the product and inevitable trend of the development of higher education in China. At the same time, Sino foreign cooperative program is not only conducive to promoting the internationalization of higher education, but also conducive to explore new development path and talent training mode of higher education. To ensure the high quality of teaching is the key problem to be solved in the course of higher education. The quality of education can be guaranteed only by the quality supervision of Chinese and foreign cooperative program.

\section{The Principles in Chinese and foreign cooperative program}

To Set up Correct understanding and the Road of the Internationalization of Higher Education. The internationalization of higher education is a complex system task and contains many various tasks of decomposition. The goal realization, or in the implementation strategy aspect, must stand in the global angle. From the view of the main body of running a school, the Chinese and foreign cooperative schools mainly involve two entities: Chinese universities and foreign universities. In the process of developing China-foreign cooperative program, China's universities must have a deep understanding that internationalization of higher education is the inevitable result of the development of global economic integration. It is irresistible that we should treat the internationalization of higher education correctly with an open attitude. At the same time, colleges and universities in China must also recognize the positive role of higher education internationalization and Sino foreign cooperative education in promoting sustainable development and broadening students' horizons. The correct understanding of the internationalization of higher education in Colleges and universities is the basic understanding of promoting Chinese and foreign cooperative program.

The Core Driving Force for the Sustainable Development of the Program. In the process of internationalization of higher education, due to the influence of diversified factors, different cooperative subjects are bound to have different purposes and requirements. It is necessary to adhere to the principle of seeking common ground for differences and winning a win-win situation in the development of Chinese and foreign cooperative schools. Adhering to this principle will help us to absorb the strengths and advantages of foreign universities and enhance the social benefits of China's Chinese and foreign cooperative program. 
Correct Understanding of the Sovereignty of Education. A correct understanding of educational sovereignty, adhering to the principles of openness and restriction and handling the relationship between them is important principles to promote long-term sustainable development of Sino foreign cooperative program. First of all, we must adhere to our educational sovereignty. Educational sovereignty is an important part of national sovereignty. It mainly refers to the power that a country possesses to coordinate various educational relations and handle educational affairs on the international level. Insisting on the inviolability of its own educational sovereignty is also a principle that a state must stick to in dealing with international educational affairs. In the exercise of their educational sovereignty, countries must not violate the basic norms of international law and must adhere to the equality of sovereignty. Secondly, the relationship between openness and restriction must be dealt with in the exercise of educational property rights. Educational property right refers to the free right of all educational subjects in the use of educational resources and so on. At the same time, in the process of implementing the educational property right, the educational subject must comply with the corresponding regulations and policy constraints, and cannot blindly pursue its own interests, regardless of the interests of other parties. Therefore, in the process of running a cooperative school, the main body of education must adhere to the principle of the combination of freedom and cooperative in the educational property.

In Chinese and foreign cooperative in running a school, Chinese colleges and universities must adhere to their own educational sovereignty. In determining the direction of the development of education, determine the education policy, understand the maintenance of our educational sovereignty and the development of China's higher education in different colleges and universities in China, adhere to based on Sino foreign cooperative education core sovereignty in the running, flexible and proper consultation and cooperative, we practice this is conducive not only to better participate in international education true, but also conducive to the realization of national interests. At the same time, along with the further development of higher education and the market continues to expand, some contrary to our national interests values have gradually emerged, had some negative impact on the development of education in China in the field of education, so that we maintain our values and the outstanding traditional culture is facing a great challenge. Therefore, it is an important link to ensure the true connotation of the educational sovereignty and the educational property right, and to deal with the relationship between them.

\section{Construction of Cooperative Teaching Quality Monitoring System}

In the process of learning, the influence of different educational systems from different countries is a significant feature of Chinese and foreign cooperative education. Practice shows that the Sino foreign cooperative education, in the process of running, because of the influence of diversification of education subject, education environment, diverse sources of information, the diversification of teaching management pattern and diversified ways of thinking and the diversification of interests, the original teaching management mode is no longer adapt to the new requirements of the running mode, so we must explore new management mode. The educational management mode of Sino foreign cooperative program is different from the conventional higher education management mode, mainly in the aspects of teaching organization form, educational evaluation mode and teaching process management and supervision. It is not difficult to find that the cultural diversity in cooperative education requires that we must adhere to the management concept of openness, inclusiveness and independent innovation in the Sino foreign cooperative program. We must build effective quality monitoring and evaluation system.

Because of the influence of various subjective and objective factors, the quality control and evaluation mechanism of Chinese and foreign cooperative schools are also different. However, all kinds of quality monitoring and evaluation mechanism and system must be established in accordance with the law of development of education and design in combination with the characteristics of Chinese and foreign cooperative program.

The scientific education quality guarantee mechanism is an important support for the long-term sustainable development of Chinese and foreign cooperative schools. Standing on the global point of 
view, in order to promote the international development of higher education in China as a goal, we should adhere to the principle of scientific and humanized, and explore the efficiency of management.

It is imperative that academic freedom and effectively serve the educational quality monitoring mechanism of Chinese and foreign cooperative program. However, because of the differences in cultural pursuit and values, the Chinese and foreign parties will also be different in the actual teaching mode. For example, the curriculum of University in our country is characterized by clear, comprehensive and meticulous, and the combination of classroom teaching and teaching material is high.

In the process of developing Sino-foreign cooperative program, we should closely combine the characteristics of two different teaching modes and the specific nature of cooperative education, and build a comprehensive scientific educational quality assurance mechanism of three levels and five vertical. The so-called three horizontal means that the construction of educational quality monitoring and guarantee mechanism should be divided into three stages: the preparation stage, the implementation stage and the optimization stage. The preparatory stage is mainly to identify all kinds of educational resources to implement Sino foreign cooperative program, and the implementation stage is mainly to monitor the specific process of teaching implementation. The optimization stage is mainly to evaluate the implementation results of teaching, and to promote reform through evaluation and evaluation. In essence, each stage and process of learning is in fact the process and stage of the emerging data. Different processes or stages are different, and the data and results are naturally different. By collecting, analyzing and summarizing the data and results produced at each stage, the efficiency of learning can be improved continuously. The so-called five vertical refers to the quality monitoring and evaluation system by participating in cooperative education school jointly composed of both sides of the joint meeting, teaching guidance committee, teaching evaluation committee and the uniform implementation of teaching management and teaching quality evaluation system consists of five aspects.

China has made clear provisions on the number of courses, quantity of courses, and number of teachers and contents of courses for both sides. Therefore, it is necessary to the process of the introduction of foreign higher education resources to adhere to the principle of patient.

\section{Strengthening the Construction of the Syllabus, and Foreign Teachers with good Professional Background and Teaching Experience.}

First of all, scientific syllabus is a necessary condition for ensuring the quality of education and teaching. Teachers with good professional background and teaching experience are the core elements to achieve high quality teaching. Arranging scientific textbooks and high-quality teachers is the core resource of teaching. Therefore, in the introduction of foreign higher education resources must adhere to the principle of identification and the introduction of absorption; insist on the introduction of high quality educational resources of high quality. Specifically, in determining the training plan and arranging the syllabus, we should pay attention to the integration of the advantages of the two courses, and build a complete knowledge system and framework suitable for Sino foreign cooperative program, so as to avoid duplication.

Secondly, the foreign teachers with high professional quality are the important factors to improve the quality of teaching in Chinese and foreign cooperative education.

In the employment of foreign teachers, we should adhere to two principles: a good background of professional knowledge and rich teaching experience.

In addition, in carrying out the process of teaching, to regularly evaluate teaching materials, selection of excellent textbooks up-to-date, so as to ensure the educational content can keep pace with the times and the development of technology. In this process, we should consider the specific characteristics of the students in our country so as to prevent the phenomenon of the students in our country.

\section{Attaching Importance to the Control of the Implementation Process.}

Practice shows that process monitoring is far more important than the result monitoring. Effective monitoring of the implementation process can guarantee the effect of implementation.

First of all, through the small class teaching form, improve the teaching model, improve the quality of teaching. Through small classes, to form a good interaction between teachers and students, teachers 
have to better master the learning situation of students; so as to timely adjust teaching strategies help students really involved in teaching activities, to ensure the dominant position of students in the classroom.

Secondly, a strong supporting mechanism is established through the construction of early warning mechanism. Strong support mechanism is a powerful guarantee for ensuring the quality of cooperative education, and the corresponding early warning mechanism is also an effective way to build a strong guarantee mechanism. Collect relevant information in teaching process regularly, analyze students' learning situation in depth, conduct early warning mechanism of students' learning and so on, so that students can timely adjust and improve learning methods, deepen their understanding of learning content, and improve their learning effect. Meanwhile, a face-to-face communication mechanism should be carried out among management personnel, teachers and students, so as to promote mutual communication and enhance the efficiency of cooperative education.

In addition, construct the corresponding teaching supervision mechanism. The teaching supervision mechanism can effectively guarantee the quality and effect of education. The construction of the educational supervision mechanism should adhere to the principle of governor and guide, supplemented by the governor and guided by the guiding principle. Through supervision, the various kinds of information about teaching are fed back to teachers and students in time to promote their continuous renewal so as to improve the quality of education.

Finally, it is necessary to establish a corresponding assessment mechanism. Assessment is a summary of teachers' teaching process and students' learning process.

Therefore, the content of the assessment should be paid attention to the assessment of the process. For example, teachers' teaching evaluation should pay attention to the teachers' teaching ideas, teaching methods, teaching contents, assessment and evaluation of specific teaching; student assessment should focus on the evaluation for the students in the learning process of participation, initiative, ability development and evaluation process etc..

\section{Continuous Improvement of the Quality of Education and Teaching.}

The quality of teaching is related to the survival and development of colleges and universities. It is the lifeline of various colleges and universities. Improving the quality of education and teaching is the core and key of the continuous development of various colleges and universities. It is the foundation for the survival and development of colleges and universities. The quality of education in Colleges and universities is ultimately reflected in the quality of talent training in Colleges and universities, and is verified by whether to meet the needs of the society. So it can be seen that students are the key and the core. The students' satisfaction with teaching, the effectiveness of the curriculum and the degree of their coincidence with the profession are the important indexes to measure the rationality of the teaching system.

First of all, the evaluation of the teaching quality of the cooperative school should be from the perspective of the peers and students. In the process of carrying out the actual evaluation, the responsibility mechanism of subject leaders and professional leaders must be set up to carry out special evaluation on the teaching process. At the same time, it is necessary to conduct a corresponding assessment of the teaching and research activities carried out by the team. In this process, the two party teachers in China and foreign countries must adhere to the principle of "the same view", and promote the integration of different teaching ideas, methods and contents.

Secondly, the students are the educated, are all the educational activities to bear, especially the main object of classroom teaching. The actual participation of the students in the classroom is a reaction to the feelings of teaching level, the teaching attitude, and the content of the teaching. And students are the main consumers of school education services. Therefore, the construction of quality monitoring system must adhere to the principle of student based. In the process of the development of teaching quality monitoring system of Sino-foreign cooperative program in the core status of different requirements and their combination of two kinds of education evaluation, the evaluation index system established for the evaluation index, students are not satisfied with the timely explanation, and timely perfect. 


\section{Conclusions}

All in all, we should take the evaluation information as an advantageous resource to improve the quality of education, and timely feedback to the actual teaching process, so as to give full play to the positive role of positive feedback. One is to optimize teachers and teaching materials, and the two is to constantly improve the teaching process. In the process of development of Sino foreign cooperative education, we must adhere to the people-oriented, to promote the ability of students for the purpose of development construction of quality monitoring mechanism through the internationalization of education atmosphere to promote the internationalization of teaching contents and teaching methods into the development of higher education reform, we learn from each other and backward teaching methods; through the integration of educational resources to students accept international education. At the same time, developing the higher education development mode of Sino foreign cooperative program can promote the internationalization process of our higher education and improve the running level and international competitiveness of higher education. At the same time, to carry out the development of higher education mode of Chinese foreign cooperative program can also broaden their international perspective provide the broader development space for them.

\section{Acknowledgements}

This work was supported by the Pilot project of comprehensive professional reform of International Economics and Trade (Joint Program, USU and NWUN) (Grant No:2017XJZYZHGGSD-01) and by Research project on education and teaching reform (Grant No:2017XJJG-12) of the Northwest Minzu University.

\section{References}

[1] Zhang Zongyuan, Research on the issue of educational property rights in China, Educational Exploration, 5(2010)5-11.

[2] Xia Jingtao, Study on the issue of educational sovereignty of Chinese and foreign cooperative education, Journal of Northeast Normal University (Philosophy Society Edition), 1(2007)3-9.

[3] Tang Zhentong, Education quality supervision mechanism of Sino foreign cooperative program, Educational Research, 2013, (12).

[4] Zhang Menghua, The distinction between educational property rights and educational sovereignty . Chinese Adult Education, 4 (2012)60-71.

[5] Mo Jane, Research on the predicament and Development Countermeasures of higher education in China, High Education Exploration, 3(2011) 12-20.

[6] Lin Yongbin, Research on the mode of running a school for higher education in China, Education and Teaching Forum, 2(2015)12-19. 